\title{
BIBECHANA
}

A Multidisciplinary Journal of Science, Technology and Mathematics

ISSN 2091-0762 (online)

Journal homepage: http://nepjol.info/index.php/BIBECHANA

\section{Thermodynamic properties of liquid InNa alloys}

\author{
A.K. Mishra ${ }^{1}$, M. Milanarun ${ }^{2 *}$ \\ ${ }^{1}$ G.B. College, Naugachia - 853 204, Bhagalpur, Bihar, India \\ ${ }^{2}$ B.S.L.I., Katihar -854105 , Bihar, India \\ *Corresponding author: E-mail : mukulmilan@yahoo.co.in \\ Article history: Received 22 November, 2012
}

\begin{abstract}
Concept of complex formation model has been applied to account for the thermodynamic properties of liquid InNa alloy. The theoretical study reveals that the intermetallic compound $\mathrm{In}_{3} \mathrm{Na}_{2}$ exists at stoichiometric composition. Our expressions reproduce successfully the asymmetric behaviour of free energy of mixing, enthalpy of mixing, s-type entropy of mixing, CSRO and phase separation in liquid In$\mathrm{Na}$ alloy. It is found that $\mathrm{Na}$ atoms segregate on the surface. The study reveals that various factors such as size difference and electronegative factor are not sufficient to account for the asymmetry in the system. The low value of order energy suggests that In-Na is a weak interacting system.
\end{abstract}

Key words: Complex formation; stoichiometric composition; phase separation; segregation; order energy.

\section{Introduction}

The anomalous behaviour in mixing properties of many binary liquid alloys needs extensive investigations. Experimentalists [1 -6] as well as theoreticians [7 - 12] have been trying to interpret the alloying behaviour of liquid alloys. The search of light weight solutions in the automotive industry [13] and importance in mechanical and technological applications in catalysis coating, high temperature engineering [14] etc. have created renewed interest in liquid binary alloys. Concentration dependent information of the thermodynamics, energetics and local atomic order is required for detailed information about the alloying behaviour of the liquid binary alloys. A good understanding of the mixing properties of liquid binary alloys is important from metallurgical point of view since most of the binary solid alloys are formed by cooling from their liquid state. Surface phenomena like surface tension play an important role in metallic systems and processes. It intervenes in nucleation from the vapour phase, in casting, coating, wetting and many other processes that include the liquid state [15]. Surface segregation is predicted in many binary liquid alloys $[11,12,16]$. Surface segregation and surface tension play an important role in metallurgical operation in the study of catalytic activity [17-21].

The concentration dependent thermodynamic properties of indium-sodium liquid binary alloys are interesting. The Gibbs energy of mixing $\left(\mathrm{G}_{\mathrm{M}}\right)$ and enthalpy of mixing $\left(\mathrm{H}_{\mathrm{M}}\right)$ are asymmetric about its equiatomic composition where as the entropy of mixing $\left(\mathrm{S}_{\mathrm{M}}\right)$ is positive at both indium and sodium rich 
ends and has negative values in the intermediate region [22]. Asymmetry in $G_{M}$ and $H_{M}$ are responsible for promoting complex formation in the liquid binary alloys, but these properties need not necessarily imply complex formation [23]. Hence the concentration-concentration fluctuations at the long wavelength limit $\left(\mathrm{S}_{\mathrm{cc}}(0)\right)$ are one of the most microscopic functions for understanding the nature of interatomic interactions. The experimental $\mathrm{S}_{\mathrm{cc}}(0)$ [24] shows both complex formation and the existence of phase separation. The contributions from entropy and enthalpy to the free energy of mixing are the physical reason responsible for phase separation [25-28]. The preference for unlike atoms to pair as the nearest neighbours i.e., hetero- coordination and preference for like atoms to pair as the nearest neighbours i.e., homo- coordination help to analyse the complex formation tendencies and the phase separation in liquid binary alloys. The asymmetry in the thermodynamic properties of In-Na liquid alloy can neither be ascribed to the size factor $\left(\Omega_{\mathrm{Na}} / \Omega_{\mathrm{In}}=1.77\right.$ being less than 2.0 , the required value to produce these effects [7] nor the electronegativity difference $\left(\mathrm{EN}=1-\exp \left(-0.25 \mathrm{~d}^{2}\right), \mathrm{d}\right.$ is the difference in the electronegativity values of the two metals) of 0.1478 [29]. So the asymmetric behaviour of various observed properties may be due to short range order.

In this study, a statistical thermodynamic model based on complex formation is used to calculate the interdependence of various properties such as free energy of mixing, heat of mixing, entropy of mixing, concentration-concentration fluctuation at long wavelength limit, chemical short range order parameter and surface tension of InNa liquid alloy. This concept has been used successfully to explain the mixing properties of a variety of binary liquid alloys [9, 10, 30, 31].

The present paper is presented as follows. A summary of essential equations required for calculations is given in section 2. Section 3 deals with results. Conclusions are summarized in section 4.

\section{Formalism}

\subsection{Properties of mixing}

The model adopted here starts by assuming the existence of A atoms, B atoms of the binary alloy AB and a chemical complexes $A_{\mu} B_{v}$ ( $\mu$ and $\nu$ being small integers) in the liquid state i.e.,

$$
\mu \mathrm{A}+v \mathrm{~B} \Leftrightarrow \mathrm{A}_{\mu} \mathrm{B}_{v}
$$

The grand partition function of an alloy consisting of $\mathrm{N}_{1}$ number of $A$ atoms and $\mathrm{N}_{2}$ numbers of $\mathrm{B}$ atoms may be expressed in terms of the configuration energy $\mathrm{E}$ as

$$
\Theta=\sum\left(\mathrm{q}_{1}(\mathrm{~T})\right)^{\mathrm{N}_{1}}\left(\mathrm{q}_{2}(\mathrm{~T})\right)^{\mathrm{N}_{2}} \exp \left[\left(\mu_{1} \mathrm{~N}_{1}+\mu_{2} \mathrm{~N}_{2}-\mathrm{E}\right) / \mathrm{K}_{\mathrm{B}} \mathrm{T}\right]
$$

where $\mathrm{q}_{\mathrm{i}}(\mathrm{T})$ and $\mu_{\mathrm{i}}$ are the atomic partition function and the chemical potential of the ith $(\mathrm{i}=1,2)$ species, respectively $K_{B}$ and $T$ refer, respectively, to the Boltzmann's constant and the absolute temperature. Equation (1) can be solved in the framework of quasi-lattice theory [32] to obtain various expressions for the thermodynamic and microscopic functions. After performing some algebra [33], we obtain the free energy of mixing as

$$
\begin{aligned}
\mathrm{G}_{\mathrm{M}} & =\mathrm{G}_{\mathrm{M}}^{\mathrm{XS}}+\mathrm{RT} \sum \mathrm{C}_{\mathrm{i}} \ln \mathrm{C}_{\mathrm{i}} \\
\mathrm{G}_{\mathrm{M}}^{\mathrm{XS}} & =\mathrm{C}_{\mathrm{i}} \mathrm{C}_{2} \mathrm{~W}+\phi_{12} \mathrm{~W}_{12}+\phi_{11} \mathrm{~W}_{11}+\phi_{22} \mathrm{~W}_{22} \\
\phi_{12} & =\mathrm{C}_{1} \mu^{-1} \mathrm{C}_{2} \mathrm{v}^{-1}\left(2-\mathrm{C}_{1} \mu^{-1} \mathrm{C}_{2} \mathrm{v}^{-1}\right) \\
\phi_{11} & =\mathrm{C}_{1} \mu^{-2} \mathrm{C}_{2} \mathrm{v}\left(2-\mathrm{C}_{1} \mu^{-2} \mathrm{C}_{2} \mathrm{v}\right): \mu \geq 2 \\
\phi_{22} & =\mathrm{C}_{1} \mu^{-2} \mathrm{C}_{2} \mathrm{v}\left(2-\mathrm{C}_{1} \mu \mathrm{C}_{2} \mathrm{v}^{-2}\right): \mathrm{v} \geq 2
\end{aligned}
$$

where $\mathrm{W}$ is the order energy and $\mathrm{W}_{12}, \mathrm{~W}_{11}, \mathrm{~W}_{22}$ are the interaction energies. $\mathrm{C}_{1}$ and $\mathrm{C}_{2}$ are the concentrations of the first and the second species of the alloys. $\phi_{\mathrm{ij}}$ is the probability of finding the $\mathrm{i}-\mathrm{j}$ 
bond as a part of the complex. In choosing an appropriate complex $\left(\operatorname{In}_{3} \mathrm{Na}_{2}\right)$ we are guided by experimental considerations [22]. For a weakly interacting system with $\mu=3, v=2$

$$
\begin{aligned}
& \phi_{12}=\left(13 / 420+2 C_{1}^{2} / 3-3 C_{1}^{3} / 2+3 C_{1}^{4} / 5+2 C_{1}^{5} / 3-5 C_{1}^{6} / 7+C_{1}^{7} / 4\right) C_{1} \\
& \phi_{11}=\left(-53 / 840+2 C_{1}^{2} / 3-5 C_{1}^{3} / 4+6 C_{1}^{4} / 5-C_{1}^{5}+4 C_{1}^{6} / 7-C_{1}^{7} / 8\right) C_{1} \\
& \phi_{22}=\left(23 / 280-C_{1}^{3} / 2+2 C_{1}^{4} / 5+C_{1}^{6} / 7-C_{1}^{7} / 8\right) C_{1}
\end{aligned}
$$

The enthalpy of mixing $\mathrm{H}_{\mathrm{M}}$ can be obtained from equation 2 and the relation

$$
\mathrm{H}_{\mathrm{M}}^{\mathrm{XS}}=\mathrm{G}_{\mathrm{M}}^{\mathrm{Xs}}-\mathrm{T}\left(\partial \mathrm{G}_{\mathrm{M}}^{\mathrm{XS}} / \partial \mathrm{T}\right)_{\mathrm{P}, \mathrm{C}, \mathrm{N}}
$$

Equations (2) and (6) yield

$$
\mathrm{H}_{\mathrm{M}}^{\mathrm{XS}}=\mathrm{C}_{1} \mathrm{C}_{2}(\mathrm{~W}-\mathrm{T}(\partial \mathrm{W} / \partial \mathrm{T}))+\sum_{\mathrm{i}, \mathrm{j}}^{1,2} \phi_{\mathrm{ij}}\left(\mathrm{W}_{\mathrm{ij}}-\mathrm{T}\left(\partial \mathrm{W}_{\mathrm{ij}} / \partial \mathrm{T}\right)\right)
$$

The entropy of mixing is given by

$$
\mathrm{S}_{\mathrm{M}}=\left(\mathrm{H}_{\mathrm{M}}-\mathrm{G}_{\mathrm{M}}\right) / \mathrm{T}
$$

\subsection{Concentration-concentration fluctuations in long wavelength limit and short range order parameter}

Concentration-concentration fluctuations in the long wavelength limit, $\mathrm{S}_{\mathrm{cc}}(0)$, have been widely used [23, $31,34,35]$ to understand the alloying behaviour of liquid binary alloys. $S_{c c}(0)$ is related to $G_{M}$ as

$$
\mathrm{S}_{\mathrm{CC}}(0)=\mathrm{RT}\left(\partial^{2} \mathrm{G}_{\mathrm{M}} / \partial \mathrm{C}_{1}^{2}\right)_{\mathrm{T}, \mathrm{P}, \mathrm{N}}^{-1}
$$

Using equation (2) the value of $\mathrm{S}_{\mathrm{cc}}(\mathrm{o})$ for $\mu=3$ and $v=2$ is given by

$$
\begin{aligned}
\mathrm{S}_{\mathrm{CC}}(0)= & \mathrm{C}_{1} \mathrm{C}_{2}\left\{1+\mathrm{C}_{1} \mathrm{C}_{2}(\mathrm{RT})^{-1}\left\lfloor-2 \mathrm{~W}+2 \mathrm{C}_{1}\left(2-9 \mathrm{C}_{1}+6 \mathrm{C}_{1}^{2}+10 \mathrm{C}_{1}^{3}-15 \mathrm{C}_{1}^{4}+7 \mathrm{C}_{1}^{5}\right)\right.\right. \\
& \mathrm{W}_{12}+\mathrm{C}_{1}\left(4-15 \mathrm{C}_{1}+24 \mathrm{C}_{1}^{2}-30 \mathrm{C}_{1}^{3}+24 \mathrm{C}_{1}^{4}-7 \mathrm{C}_{1}^{5}\right) \mathrm{W}_{11}+\mathrm{C}_{1}^{2} \\
& \left.\left.\left(-6+8 \mathrm{C}_{1}+6 \mathrm{C}_{1}^{3}-7 \mathrm{C}_{1}^{4}\right) \mathrm{W}_{22}\right]\right\}^{-1}
\end{aligned}
$$

The Warren-Cowley [36, 37] short range order parameter, $\alpha_{1}$ is evaluated to quantify the degree of order and is computed theoretically $[23,31,37]$ as

$$
\begin{gathered}
\left.\alpha_{1}=(\mathrm{S}-1) /(\mathrm{S}(\mathrm{Z}-1)+1)\right) \\
\mathrm{S}=\mathrm{S}_{\mathrm{CC}}(0) / \mathrm{S}_{\mathrm{CC}} \operatorname{id}(0) \\
\mathrm{S}_{\mathrm{CC}} \mathrm{id}(0)=\mathrm{C}_{1} \mathrm{C}_{2}
\end{gathered}
$$

Here $\mathrm{Z}$ is the coordination number, which is taken as 4 for In-Na liquid alloy [8]. 


\subsection{Surface tension}

The surface tension of complex forming liquid alloys is given by [10, 38, 39]

$$
\begin{aligned}
\sigma & =\sigma_{1}+(\mathrm{RT} / \mathrm{A})\left[\ln \left(\mathrm{C}_{1}^{\mathrm{S}} / \mathrm{C}_{1}\right)+\ln \left(\gamma_{1}^{\mathrm{S}} / \gamma_{1}\right)\right] \\
& =\sigma_{2}+(\mathrm{RT} / \mathrm{A})\left[\ln \left(\mathrm{C}_{2}^{\mathrm{S}} / \mathrm{C}_{2}\right)+\ln \left(\gamma_{2}^{\mathrm{S}} / \gamma_{2}\right)\right]
\end{aligned}
$$

where, $\sigma_{i}(i=1,2)$ are the surface tensions of the components and $A$ is the mean atomic surface area. $\gamma_{i}^{\mathrm{s}}$ and $C_{i}^{s}$ refer, respectively, to activity coefficients and the concentrations of the ith component at the surface. $\gamma_{\mathrm{i}}^{\mathrm{s}}$ is the related to $\gamma_{\mathrm{i}}$ as

$$
\ln \gamma_{i}^{S}=n_{1}\left(\ln \gamma_{i} \text { containing } C_{i}^{S}\right)+n_{2} \ln \gamma_{i}
$$

where $\mathrm{n}_{1}$ and $\mathrm{n}_{2}$, termed as surface coordination fractions, are the fractions of the total numbers of nearest neighbours of an atom within the layer in which it lies and that in the adjoining layer, respectively, so that $\mathrm{n}_{1}+2 \mathrm{n}_{2}=1$. From equation (2) and the usual thermodynamic relation

$$
\mathrm{G}_{\mathrm{M}}^{\mathrm{XS}}=\mathrm{N} \int_{0}^{\mathrm{C}_{1}} \ln \gamma \mathrm{dC_{1 }}
$$

the activity coefficients for $\mu=3$ and $v=2$ are given as :

$$
\begin{aligned}
& \ln \gamma_{1}=\left(\mathrm{K}_{\mathrm{B}} \mathrm{T}\right)^{-1}\left[\mathrm{~W}\left(1-\mathrm{C}_{1}\right)^{2}+\mathrm{W}_{12}\left(13 / 420+\mathrm{C}_{1}^{2}-22 \mathrm{C}_{1}^{3} / 3+15 \mathrm{C}_{1}^{4} / 2+8 \mathrm{C}_{1}^{5} / 5\right.\right. \\
& \left.-25 \mathrm{C}_{1}^{6} / 3+44 \mathrm{C}_{1}^{7} / 7-7 \mathrm{C}_{1}^{8} / 4\right)+\mathrm{W}_{11}\left(-53 / 840+2 \mathrm{C}_{1}^{2}-19 \mathrm{C}_{1}^{3} / 3\right. \\
& \left.+39 \mathrm{C}_{1}^{4} / 4-54 \mathrm{C}_{1}^{5} / 5-9 \mathrm{C}_{1}^{6}+31 \mathrm{C}_{1}^{7} / 7+{ }^{7 \mathrm{C}_{1}^{8} / 8}\right)+\mathrm{W}_{22}\left(23 / 280-2 \mathrm{C}_{1}^{3}\right. \\
& \left.\left.+{ }^{7} \mathrm{C}_{1}^{4} / 2-8 \mathrm{C}_{1}^{5} / 5+\mathrm{C}_{1}^{6}-13 \mathrm{C}_{1}^{7} / 7+7 \mathrm{C}_{1}^{8} / 8\right)\right] \\
& \ln \gamma_{2}=\left(\mathrm{K}_{\mathrm{B}} \mathrm{T}\right)^{-1}\left[\mathrm{WC}_{1}^{2}+\mathrm{W}_{12}\left(-4 / 3+9 \mathrm{C}_{1} / 2-12 \mathrm{C}_{1}^{2} / 5-10 \mathrm{C}_{1}^{3} / 3+30 \mathrm{C}_{1}^{4} / 7\right.\right. \\
& \left.-7 \mathrm{C}_{1}^{5} / 4\right) \mathrm{C}_{1}^{3}+\mathrm{W}_{11}\left(-4 / 3+15 \mathrm{C}_{1} / 4-24 \mathrm{C}_{1}^{2} / 5+5 \mathrm{C}_{1}^{6}-24 \mathrm{C}_{1}^{4} / 7\right. \\
& \left.\left.+9 \mathrm{C}_{1}^{5} / 8\right) \mathrm{C}_{1}^{3}+\mathrm{W}_{22}\left(3 / 2-8 \mathrm{C}_{1} / 5-6 \mathrm{C}_{1}^{3} / 7+7 \mathrm{C}_{1}^{4} / 8\right) \mathrm{C}_{1}^{4}\right]
\end{aligned}
$$




\section{Results and Discussion: Comparison between calculation and experiment}

\subsection{Mixing properties}

The free energy of mixing $\left(\mathrm{G}_{\mathrm{M}}\right)$ of liquid In-Na alloy at $713 \mathrm{~K}$ has been computed through equation (2). Those values of order energy and interaction energies are considered which when substituted into equation (2) give us values of $G_{M}$ that are very close to experimentally observed values from [22]. These parameters are independent of concentration although they may depend on temperature and pressure. These computed values are

$$
\mathrm{W}=1.66 \mathrm{RT} \quad \mathrm{W}_{11}=-18.99 \mathrm{RT} \quad \mathrm{W}_{22}=-6.84 \mathrm{RT} \quad \mathrm{W}_{12}=-1.9 \mathrm{RT}
$$

It is obvious from the value of order energy $\mathrm{W}$ that the tenderly of complex formation in the alloy InNa is relatively weak. The values of interaction energy suggest that attraction between In atoms is maximum followed by $\mathrm{Na}$ atoms and $\mathrm{In}$ and $\mathrm{Na}$ atoms.

A plot of computed and experimental [22] values of $\mathrm{G}_{\mathrm{M}} / \mathrm{RT}$ for InNa liquid alloy at $713 \mathrm{~K}$ is given in figure 1. Figure 1 shows that computed and experimental values are in agreement.
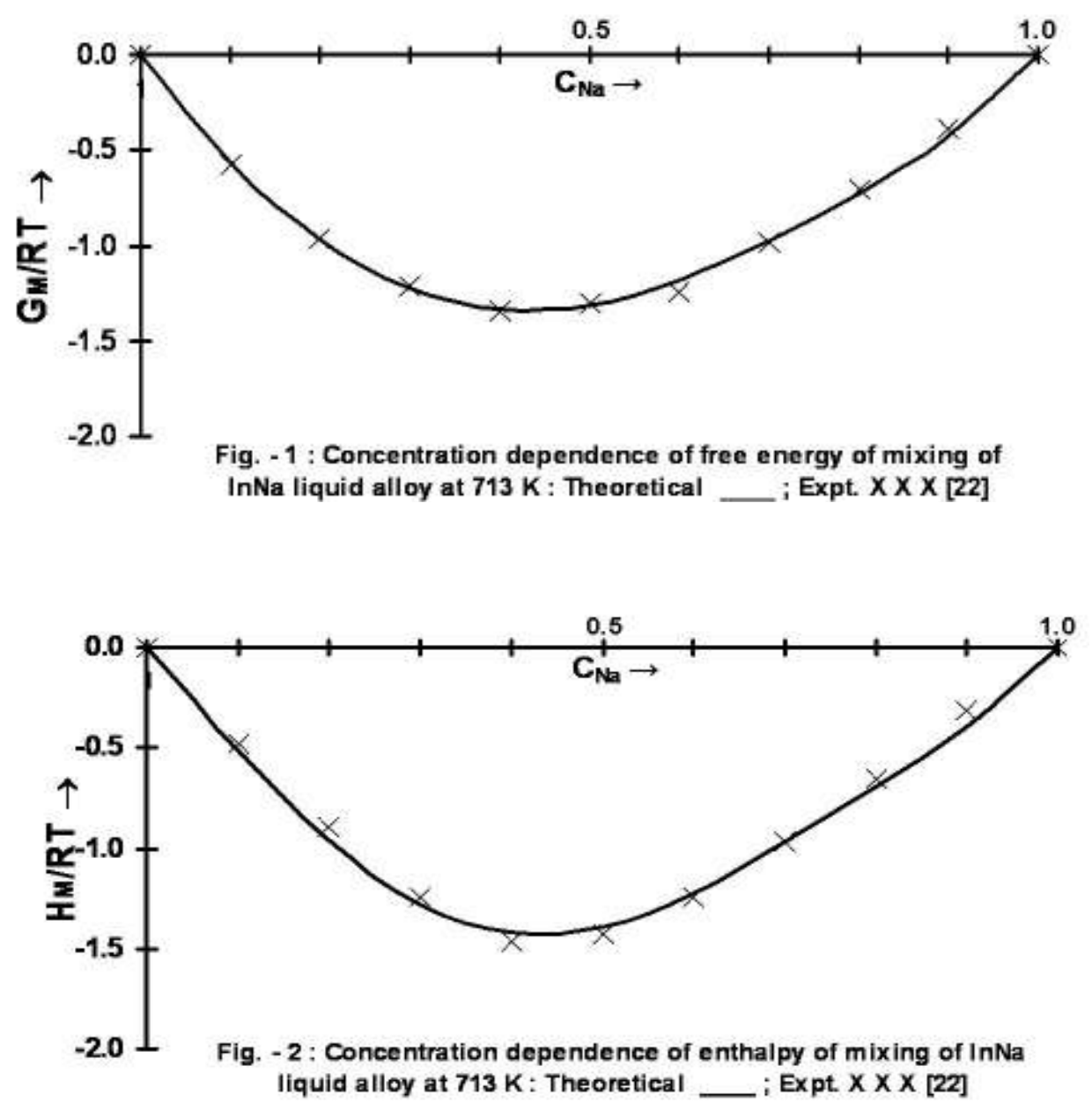
The enthalpy of mixing $\left(\mathrm{H}_{\mathrm{M}}\right)$ and entropy of mixing $\left(\mathrm{S}_{\mathrm{M}}\right)$ are evaluated through equations (7) and (8) respectively. The energy parameters are considered to vary with temperature to ascertain the variation of enthalpy and entropy of mixing with experimental values [22]. The temperature dependent energies are

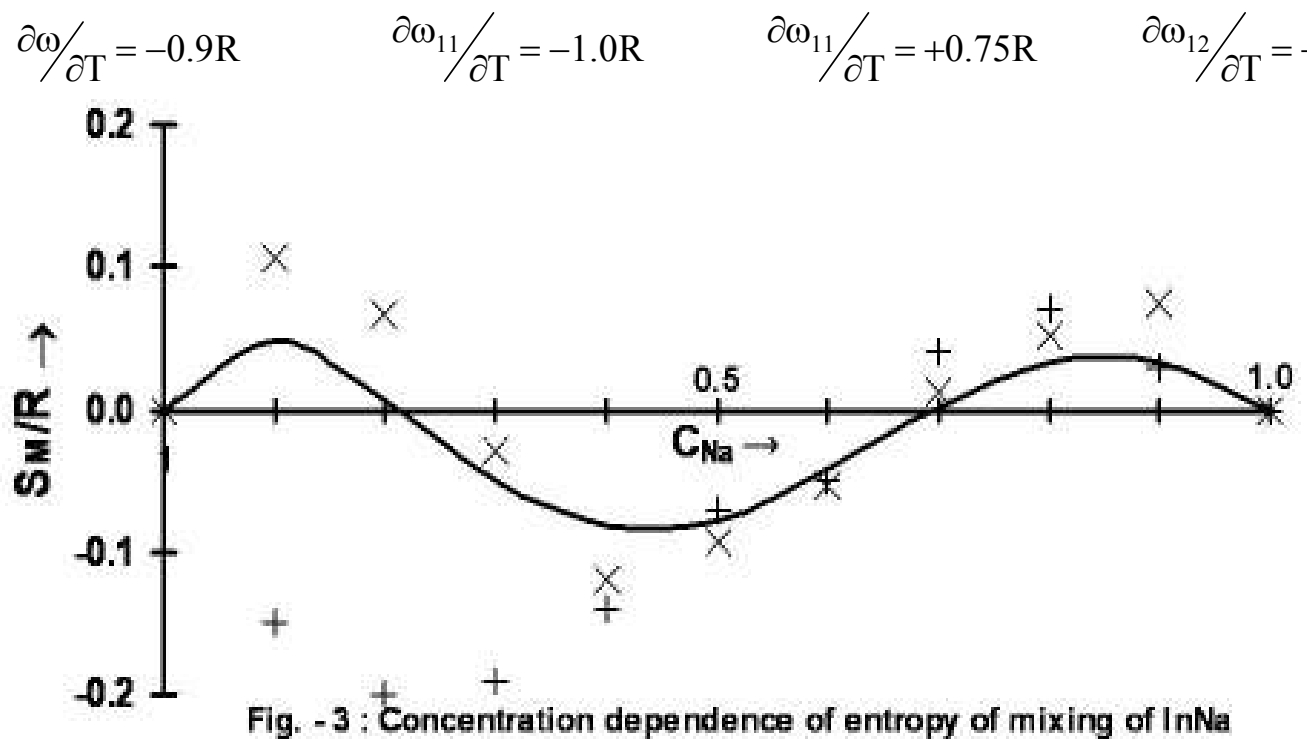
liquid alloy at $713 \mathrm{~K}$ : Theoretical ; Expt. X X X [22]; +++[40]

The values of enthalpy of mixing $\mathrm{H}_{\mathrm{M}} / \mathrm{RT}$ and entropy of mixing $\mathrm{S}_{\mathrm{M}} / \mathrm{R}$ for In-Na liquid alloy at $713 \mathrm{~K}$ are shown in figures 2 and 3 respectively along with experimental values [22]. It is seen from figure 2 that the computed values of $\mathrm{H}_{\mathrm{M}} / \mathrm{RT}$ are in reasonable agreement with experiment. It is clear from figure 3 that the pattern of $S_{M} / R$ is reproduced in our computation. But calculated values are not in quantitative agreement with the experiment. It may be because of the fact that slight difference in $G_{M} / R T$ and $H_{M} / R T$ produces more difference between the computed and experimental values of $\mathrm{S}_{\mathrm{M}} / \mathrm{R}$ as is evident from equation 8 . However, our computed values are better than that given by Chakrabarti et al [40].

\subsection{Concentration-concentration fluctuations in the long wavelength limit $S_{c c}(0)$ and short range order parameter $\left(\alpha_{1}\right)$}

$\operatorname{Scc}(0)$ is an important parameter because any deviation from ideal value Scc id (0) is significant in explaining the type of interaction in liquid alloys. There is a tendency for self coordination if $\operatorname{Scc}(0)>\operatorname{Scc}$ id (0) and Scc $(0)>>$ Scc id (0) means the occurrence of phase separation. Scc $(0)<<$ Scc id (0) is an indication of the existence of chemical short range order (CSRO) or an indication of strong association. The values of Scc (0) are computed via equation (10). These are depicted in figure 4 along with experimental values [24], values computed by Akinlade [8] and Scc id (0). Perusal of figure 4 indicates that the computed values of Scc $(0)$ predicts $\mathrm{CSRO}$ in the concentration range $0<\mathrm{C}_{\mathrm{Na}}<0.7$ and phase separation in $0.7 \leq \mathrm{C}_{\mathrm{Na}} \leq 1.0$. The magnitude of the calculated values beyond $\mathrm{C}_{\mathrm{Na}}>0.7$ is lower than the experimental values. A better agreement between the calculated and experimental values may be obtained if the energy parameters are assumed concentration dependent. The dip in $\mathrm{S}_{\mathrm{CC}}(0)$ is found at stoichiometric composition $\mathrm{In}_{3} \mathrm{Na}_{2}$. 
The short range order parameter $\alpha_{1}$ has been calculated to quantify the degree of order and these have been represented in figure 5. The negative values of $\alpha 1$ correspond to complex formation while its positive values correspond to the occurrence of segregation resulting in phase separation. A random distribution of atoms is expected by $\alpha_{1}=0$.
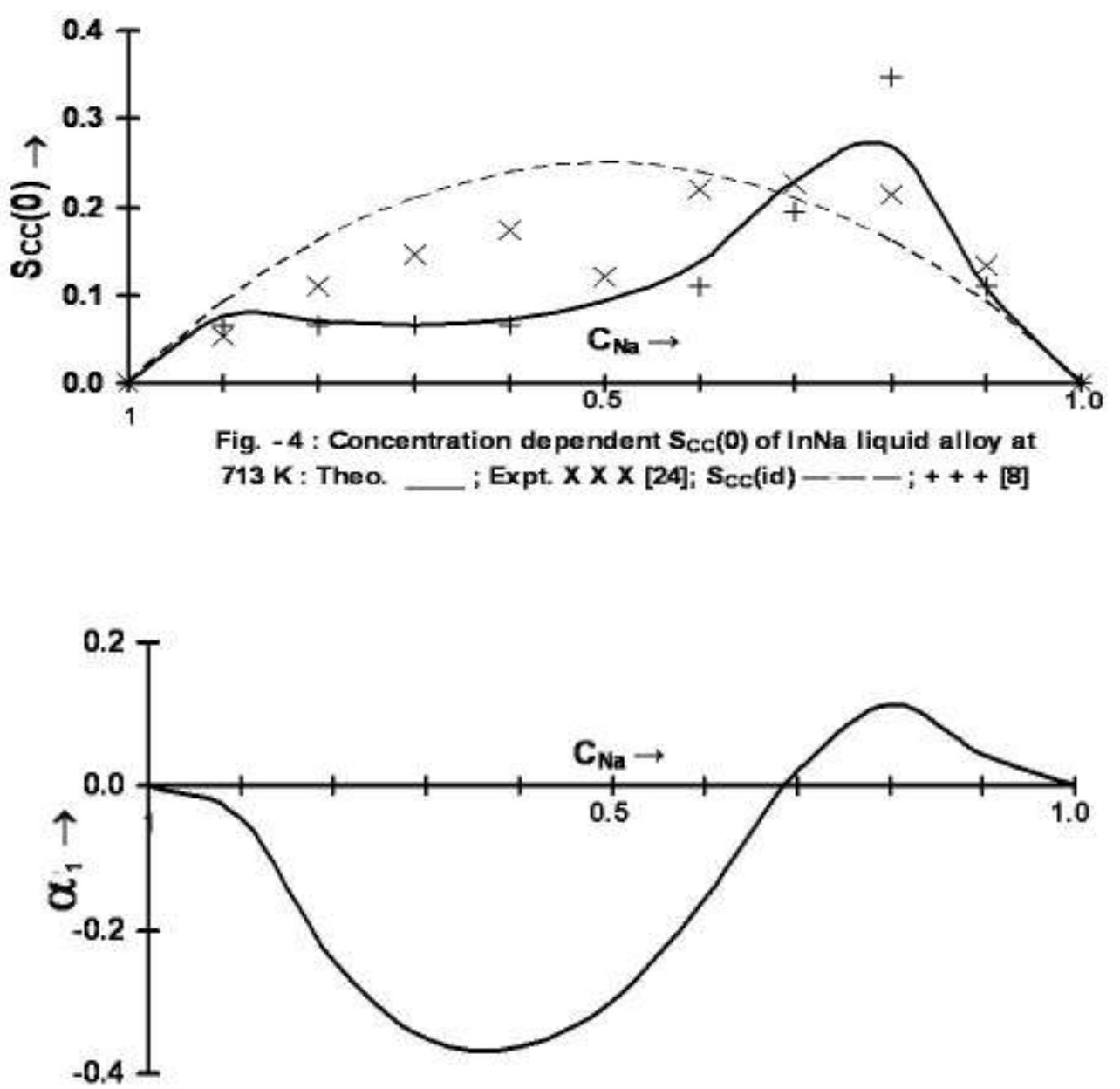

Fig. - 5 : Concentration dependent $\alpha_{1}$ of $\ln N a$ liquid alloy at $713 \mathrm{~K}$

\subsection{Surface tension}

Calculation of surface tension through equations $(14 \mathrm{a}, 14 \mathrm{~b})$ requires the values of surface concentration $C_{i}^{S}(i=1,2)$ and activity coefficients in the bulk $\gamma_{i}$ and on the surface $\gamma_{i}^{S}$. The calculated values of $\gamma_{1}$ and $\gamma_{2}$ along with experimental values [22] and calculated values of $\gamma_{i}^{S}$ and $\gamma_{2}^{\mathrm{S}}$ are given in table 1. Table 1 shows that there is reasonable resemblance between calculated and experimental values of activity coefficients of In $\left(\gamma_{1}\right)$ and $\mathrm{Na}\left(\gamma_{2}\right)$ in the bulk in InNa liquid alloy at $713 \mathrm{~K}$. It is predicted from table 1 that sodium atoms are more active on the surface than in the bulk throughout the whole concentration range except for $\mathrm{C}_{\mathrm{Na}}=0.9$. Indium atoms are less active on the surface than in the bulk up to $\mathrm{C}_{\mathrm{Na}}<0.5$ but become more active on the surface than in the bulk after this concentration. 
Table 1 : Activity coefficients of In and $\mathrm{Na}$ in InNa liquid alloy at $713 \mathrm{~K}$ in the bulk $\left(\gamma_{1}, \gamma_{2}\right)$ and on the surface $\left(\gamma_{1}^{S}, \gamma_{2}^{S}\right)$

\begin{tabular}{|c|c|c|c|c|c|c|}
\hline \multirow{2}{*}{$\mathrm{C}_{2}$} & \multicolumn{2}{|c|}{$\gamma_{1}$} & \multirow{2}{*}{$\gamma_{1}^{S}$} & \multicolumn{2}{|c|}{$\gamma_{2}$} & \multirow{2}{*}{$\gamma_{2}^{S}$} \\
\cline { 2 - 3 } \cline { 5 - 6 } & Theoretical & Expt. [22] & & Theoretical & Expt. [22] & \multirow{2}{*}{0.165} \\
\hline 0.1 & 1.003 & 0.978 & 0.871 & 0.065 & 0.097 & 0.518 \\
\hline 0.2 & 0.921 & 0.900 & 0.548 & 0.082 & 0.151 & 0.714 \\
\hline 0.3 & 0.727 & 0.752 & 0.521 & 0.252 & 0.258 & 0.855 \\
\hline 0.4 & 0.511 & 0.554 & 0.509 & 0.505 & 0.454 & 0.959 \\
\hline 0.5 & 0.353 & 0.365 & 0.456 & 0.844 & 0.765 & 1.010 \\
\hline 0.6 & 0.268 & 0.248 & 0.422 & 1.044 & 1.044 & 1.021 \\
\hline 0.7 & 0.247 & 0.207 & 0.412 & 1.086 & 1.156 & 1.010 \\
\hline 0.8 & 0.280 & 0.227 & 0.424 & 1.042 & 1.126 & 1.000 \\
\hline 0.9 & 0.347 & 0.356 & 0.447 & 1.003 & 1.004 & \\
\hline
\end{tabular}

Surface tension of InNa liquid alloy is calculated at $713 \mathrm{~K}$ using equation 14 . The surface tension of pure In and $\mathrm{Na}$ at the specified temperature are taken from Smithell's Metals Reference Book [41]. The mean atomic surface area $\mathrm{A}$ is calculated from the relation given by Laty et al. [42] as

$$
\mathrm{A}=1.102(\mathrm{~V} / \mathrm{N})^{2 / 3}
$$

where $\mathrm{N}$ is the Avogadro's number and V is the volume the alloy. Experimental values of $\mathrm{V}$ have been taken from the graph given by Akinlade [8]. The evaluated values of surface tension of InNa liquid alloy with concentration are displayed in table 2 along with its ideal values $\left(\sigma=\mathrm{C}_{1} \sigma_{1}+\mathrm{C}_{2} \sigma_{2}\right)$ and surface concentration of $\mathrm{Na}$.

Table 2 : Surface concentration of $\mathrm{Na}\left(C_{2}^{S}\right)$ and surface tension $(\sigma)$ of InNa liquid alloy at $713 \mathrm{~K}$.

\begin{tabular}{|c|c|c|c|}
\hline $\mathrm{C}_{2}$ & $C_{2}^{S}$ & $\sigma$ & $\sigma_{i d}\left(=C_{1} \sigma_{1}+C_{2} \sigma_{2}\right)$ \\
\hline 0.1 & 0.2866 & 494.713 & 493.550 \\
\hline 0.2 & 0.5372 & 430.553 & 457.407 \\
\hline 0.3 & 0.8569 & 355.470 & 420.863 \\
\hline 0.4 & 0.9634 & 283.708 & 384.320 \\
\hline 0.5 & 0.9884 & 233.436 & 347.777 \\
\hline 0.6 & 0.9954 & 203.578 & 311.233 \\
\hline 0.7 & 0.9977 & 187.859 & 274.690 \\
\hline 0.8 & 0.9987 & 179.337 & 238.146 \\
\hline 0.9 & 0.9994 & 172.421 & 201.603 \\
\hline
\end{tabular}

We could not compare our evaluated values for want of experimental values. Table 2 shows that the surface tension of In is lowered when alloyed with $\mathrm{Na}$, The value of surface tension InNa liquid alloy is above its ideal values up to $10 \%$ concentration of $\mathrm{Na}$ and after this the calculated values are less than its ideal values. It is evident from table 2 that $\mathrm{Na}$ atoms segregate on the surface at all concentrations. 


\section{Conclusion}

The phenomenon of complex formation in InNa liquid alloys and its effect on the concentration dependent mixing properties were investigated theoretically on the basis of quasi-lattice theory. The existence of the complex in the form $\operatorname{In}_{3} \mathrm{Na}_{2}$ has been used to obtain concentration dependent thermodynamic properties and surface tension of InNa liquid alloy. The low value of order energy (W/RT) shows that InNa liquid alloy is a weak interacting system. The evaluation of $\mathrm{S}_{\mathrm{CC}}(0)$ predicts that $\mathrm{CSRO}$ exists in the region $0<\mathrm{CNa}<0.7$ and phase separation in the region $0.7<\mathrm{CNa} \leq 1.0$. A better agreement between theoretical and experimental values of $\mathrm{S}_{\mathrm{CC}}(0)$ at $\mathrm{C}_{\mathrm{Na}}=0.8$ can be obtained by assuming concentration dependent energy parameters but it may distort the quasi-lattice theory. The same energy parameters have been considered for the study of bulk as well as surface properties. We may conclude that the theory is capable of predicting of negative values of free energy of mixing, enthalpy of mixing, s-type entropy of mixing, the phenomenon of CSRO and phase separation by considering $\operatorname{In}_{3} \mathrm{Na}_{2}$ complex in $\operatorname{InNa}$ liquid binary alloys.

\section{References}

[1] H.E. Barleett, A.H. Neethling and P.J. Growther, J. Chem. Thermodyn., 2 (1970) 521.

[2] P. Chieux and J. Ruppersberg, J. Physique C8, 41 (1980) 321.

[3] S. Takeda, S. Tamaki, S. Harda and N.E. Cusack, J. Phys. Condens. Matter, 1 (1989) 8649.

[4] S. Takeda and S. Tamaki, J. Phys. Condens. Matter, 2 (1990)10173.

[5] Y. Tsuchiya and S. Kanai, J. Non-Cryst. Solids, 156 - 158 (1993) 433.

[6] I.S. Choi, C.N. Whang and C. Hwang, J. Phys. Condens Matter, 15 (2003) L 415.

[7] R.N. Singh and F. Sommer, J. Phys. Condens Matter, 4 (1992) 5345.

[8] O. Akinlade, Z. Metallkd., 85 (1994) 487.

[9] L.C. Prasad and A. Mikula, J. Alloys and Comp., 299 (2000) 175.

[10] N. Jha and A.K. Mishra, J. Alloys and Comp., 329 (2001) 224.

[11] A.K. Mishra and M. Milanarun, Hingh Temp. Mat. and Process, 24 (2005) 47.

[12] V. Kumari and A.K. Mishra, High Temp Mat. and Process, 27 (2008) 113.

[13] K.N. Braszczynska, Z Metallkd., 94 (2003) 144.

[14] A.N. Al-Rawi, A. Kara and T.S. Rahman, J. Phys. Condensed Matter, S2 (2004) 967.

[15] A.R. Yavri, Z. Metallkd., 79 (1988) 591.

[16] M. Brejnak and P. Mudrak, J. Phys. Condensed Matter, 2 (1990) 869.

[17] P. Vander Plank and W.M.H. Sachter, J. Catal., 7 (1968) 300; 12 (1968) 35.

[18] W.M.H. Sachter and P. Vander Plank, Surf. Sci., 18 (1969) 62.

[19] H. Sinfelt, Bimetallic Catalysis; Discoveries, Concept Applications, John Wiley \& Sons, New York (1983).

[20] K.S. Yeum, R. Speiser and D.R. Poirier, Metall. Trans., 208 (1989) 693.

[21] Z. Moser and M. Kucharsky, J. Non - Cryst. Solids., 156 - 158 (1993) 369.

[22] R. Hultgren, P.D. Desai, D.T. Hawkins, M. Gleiser and K.K. Kelley Selected Values the of Thermodynamic Properties of Binary Alloys, ASM Metals Park, Ohio (1973) 1013.

[23] P.P. Mishra, M. Milanarun, N. Jha and A.K. Mishra, J. Alloys and Comp., 340 (2002) 108.

[24] S. Harda, S. Takahashi, S. Takeda, S. Tamaki, P. Gray and N.E. Cusack, J. Phys. F, 18 (1988) 2259.

[25] L.S. Leowitz and L.S. Rawlinsonm, J. Chem. Phys., 41 (1964) 133.

[26] T. Biben and J.P Hansen, Phys. Rev. Lett., 66 (1991) 2215.

[27] D. Frenkel and A.A. Louis, Phys. Rev. Lett., 68 (1992) 3363.

[28] S.M. Osman and R.N. Singh, Phys. Rev., E 51 (1995) 332.

[29] F. Hensel, Adv. Phys., 28 (1979) 555.

[30] R.N. Singh, I.S. Jha and S.K. Singh, J. Phys. Condens Matter, 3 (1993) 2787.

[31] A.K. Mishra and M. Milanarun, Indian J. Phys., 80 (2006) 55.

[32] A.B. Bhatia and R.N. Singh, Phys. Chem. Liq., 11 (1982) 343. 
[33] A.B. Bhatia and D.E. Thronton, Phys. Rev. B, 2 (1970) 3004.

[34] C.N.J. Wagner, S. Steeb and H. Warlmout, Rapidly Quenched Metals Amsterdam North-Holland (1985).

[35] R.N. Singh, Can. J. Phys., 65 (1987) 309.

[36] B.E. Warren, X - ray Diffraction (Reading M. A. Addison - Wesley) (1969).

[37] J.M. Cowley, Phys. Rev. B, 77 (1950) 667.

[38] R.D. Angal and D.L. Roy, Z. Metallkd., 73 (1982) 428.

[39] A.K. Mishra, High Temp. Mat. and Process., 26 (2007) 201.

[40] S.K. Chakrabarti, I.S. Jha and B.P. Singh, Scientific World, 6 (2008) 16.

[41] E.A. Brandes and G.B. Brook (eds), Smithell's Metals Reference Book, Oxford; Butter Worth - Heinemann (1992).

[42] P. Laty, J.C. Loud and P. Deste, Surf. Sci., 60 (1976) 109. 